\title{
The strategies of managing the human resources and their relation to the organizational trust of the sports trainers who work at the Egyptian sports clubs (an analytical study)
}

Dr/ Deina Hanfy Abdel Aziz

The problem and importance of the research:

The last period has witnessed large changes and an increase in the world competition in different fields, so, all organizations should increase its competitive ability through the renewal, innovation, and initiative, discovering and exploiting the opportunities. The organization can not achieve this but through the human resources who have high rate of ability, skill, efficiency and motivation one high indicators of the ordering trust in their organizations, enrich in regarded us

The working human resources in each organization are groups of individuals who are able to work and have the desire to perform their work in obligatory and in hard way. At the level of the organization, the human resources management is considered as strategic entrance for managing the most important principals of the organization; namely, the workers of the organization who contribute individually or collectively for achieving its goals (Ahmed Sayed Mustafa 2010).

Thus, the human element plays an important role in building the competitive advantage for the organizations; this made a lot of organizations consider the human element as one of the most resources, since they think that the successful organizations are those which can get the human resources with rare skills and abilities (Mohammed Mohammed Ibrahim 2009).

The human resources who have the ability of renewal, innovation and development, they also can overcome the scarcity of the organization's resources through exploiting the organization resources ideally as well as the rational exploitation for all available investments and resources (Mahfouz Gowda Ahmed 2010). 
Accordingly, the human resources are the assts owned by the organization, since the human resources are those who invent, renew, organize and execute the works. All potentialities and resources available at the organization can be wasted unless there are the active human resources that can them positively (Mohammed Sayed Gad Al Rab 2009).

\section{Introduction}

The strategy of managing the human resources constitutes a set of strategies and plans directed for managing the work which relate to attracting, choosing the human resources and comparing, employing and evaluating their performance, defining the systems of their incentives and compensating them as well as training and developing their levels with the aim of achieving the organization's strategic goals and facing the changes that can occur in the light of the changeable conditions (Sakina Al Mohal \& Ahmed Ibrahim 2013).

On other hand, the organizational trust is considered as one of the most important pillars that help the organizations to support its activities and to achieve its goals. It is also considered as one of the most effective administrative tools since they create the proper conditions for the success of the organizations. When there is more trust inside the organization, the individuals can express their ideas and opinions, and the also can cooperate with each other. On the contrary, as for the organizations that lack the trust, there will be kind of disappointment, non cooperation and the weak communication

(Ahmed Hassan Al Wazzab 2012).

The organizational trust is a set of the common predictions between two parties, since each part considers this trust as unwritten physiological contract which organize the obligations of each party mentally and behaviorally, accordingly, there will be a mutual trust that governs the relation between the two parties despite be unwritten or non obliged legally; but it is the only standard for evaluating the relation between the two parties (Asmma Taha Noury 2008). 
The importance of the organizational trust contributes in creating the cooperation and achieving the goals, it also contributes in creating an integrated and comprehensive control, in addition to its ability to establish the credibility of the control efforts through emphasizing the response of the organization members and their acceptance to the internal policies and decisions as well as their recognition to the lines of authority and responsibility, since the trust has become a system for the symbolic control that helps in reducing the complications of the control systems (Fahmy Khalil Al Fahdawy 2005).

Thus, the organizational trust is considered as a basic demand for transforming from depending on observation and control into depending on the information and self knowledge and control in order to march the current developments and to face the challenges. Accordingly, the trust needs to the ability of learning, adaption and strictness and it also needs to the good communication as well as the accuracy and the flow of information (Zyad
Yousef Al Masher \& Magdoline Assry 2012).

Therefore, there is an emphasize on establishing the organizational trust between the concerned parties; since it is an important factor in reaching the integration of the organization because the working with individuals or in groups needs to the mutual dependence for achieving the organizational goals. The organizational trust is basic and essential matter for understanding both the individual and group behavior as well as understanding the administrative activities and the occupational growth (Saad Ali Al Anzy \& Moayed Yousef Neama 2004).

Form this point, the organizational trust is considered as an important factor in the organizational behavior because it has become as essential factor in supporting the organizations' success for the long term, in particular after increasing the competition. Thus, it is necessary to depend on strengthening the relations among the individuals based on the trust and integrity, in particular, after increasing the dependence on the information, 
it is expected to increase the importance of the trust on the organizational development to the extent of easing the process of making the decisions (Rana Nasser Al Taay 2007).

Thus, the organizational trust has become as the competitive strength that is added on the level of organizations since it contributes in restricting the selfishness attitudes and reduces the efforts made for controlling what is called as the bureaucratic routine (A'amer Khodir Al Kebisy 2011).

On the other hand, the sports club is considered as sports authority with an independent artificial character and it is also considered as one of the special authorities with the public benefit. The club also aims to forming the integrated character of youth in relation to the social, health, religious, psychological and recreation aspects through the spread of the physical and social education, creating the spirit of patriotism between the organization members, developing their talents and easing the means for spending their free times. The club also practices his specialties in the light of the state public policy and the planning made by the national council for the sport. It also organizes its formal sports activity according to the basics and programs made by the concerned associations of different games.

The club can take all ways and means for achieving these goals, in particular: supporting the religious and national spirit, paying attention to the healthcare of its members, organizing the health card of each player, organizing the activities of upbringing and the national preparation as well as the sports and social activities.

The club also practices his specialties in the light of the state public policy and the planning made by the national council for the sport. It also organizes its formal sports activity according to the basics and programs made by the concerned associations of different games. (the regularity of the basic system of the sports clubs- 2013).

The researcher sees that the practical reality indicates to the existence of many challenges, obstacles and variables that face the Egyptian sports clubs as result of the 
changes that occur in the external environment that is full of many competitive challenges that make it is difficult to the sports clubs to gain it competitive advantage and in order to be active through managing its human resources only. It has become clear that, as result of many researchers, the organizational trust plays an active role in the organizational performance of the organization on all administrative levels; it is the mean that contributes in enlarging the cooperation and the common work between these human resources that were chosen, appointed and trained for achieving these hoped goals.

Based on the scientific and practical importance for both of the strategies of managing the human resources and the organizational trust in the life of the sports organizations in general and the sports clubs in particular, this study has been conducted and is considered as new vision for finding relationship between two variables that haven't been correlated in any study before according the researcher's knowledge.
First: the theoretical
importance:
The importance of the research in enriching the Arabic sports library with the following scale:

1- The questionnaire of the strategies of human resources management for the trainers of the sports activities at the Egyptian sports clubs.

2- The scale of the organizational trust for the trainers of the sports activities in the Egyptian sports clubs.

\section{Second: The practical importance:}

The importance of the practical importance lies in the following points:

1- The current study provides the decision- makers with strategic data about the reality of strategies for managing the human resources inside the sports clubs. It can be used in defining the strategies that need to be supported and strategies need to be modernized.

2- The current study provides data and indicators about the reality of the organizational trust inside the sports clubs that can be used in defining the priorities that aim to improve 
the organizational trust in their organizations.

3- This study provides indicators with practical importance about the relation between the strategies of managing the human resources and the organizational trust. These indicators can be used in developing and modernizing the strategies of managing the human resources to get use of its positive role in achieving the organizational trust in their sports organizations.

4- The current study provides the leaders in the sports field with information about the most important strategies for managing the human resources that affect positively on the level of the organizational trust for the sports trainers.

\section{The aim of the research}

This research aims to study the relationship between the strategies of managing the human resources and the organizational trust for trainers of sports activities inside the Egyptian clubs through defining the following:

1- The strategies of managing the human resources in the Egyptian sports clubs.

2- The degree of the organizational trust possessed by the trainers of the sports activities in the Egyptian clubs. 3- The relationship between the strategies of managing the human resources and the organizational trust for the trainers of the sports activities in the Egyptian clubs.

\section{The research questions:}

The research responds to the following questions:

1- What are the strategies of managing the human resources in the Egyptian sports clubs?

2- What is the degree of the organizational trust possessed by the trainers of the sports activities in the Egyptian clubs?

3- What is the relationship between the strategies of managing the human resources and the organizational trust for the trainers of the sports activities in the Egyptian clubs?

The terms used in this research:

The strategies of managing the human resources:

The strategies of managing the human resources can be defined as "the strategic management that concerns with forming the strategies and policies of the human resources in accordance with the environmental opportunities, 
the works strategies and the organizational structure with the aim of achieving the completive advantages by the human element (Caliskhan, Esra, 2010).

The researcher defines the strategies of managing the human resources in the sports clubs as "the procedures that emerge from the strategic plan of the club that aim to the planning, organizing, coordination, controlling and guiding the human resources through achieving the effectiveness of the human resources system and adaptation to the current internal and external conditions as well as the future conditions of these clubs (a procedural definition).

The strategy of attraction, choice and appointment:

The

strategy

of

attraction, choice and appointment is defined as "the integrated that are followed to attract, elect and appoint the employees in the organization with the aim of securing the proper human resources for the organization for meeting its needs in the proper time (Cook, F 2010).

- The researcher defines the strategy of attraction, choice and appointment is defined as "the ways and standards of motivating and attracting the distinguished human elements for choosing the best of them to work at the club with the aim of meeting its current and future needs of the human resources, quantity and quality, in the proper time, through the continuous modernization for the ways and methods of searching for the required human resources as well as developing the means of examining and choosing the proper personnel to work at the club" (a procedural definition).

The research procedures:

The used methodology:

The researcher used the descriptive methodology since it is proper to the research subject.

\section{The research society}

The research society included the sports trainers who work in the sports clubs in the Arab Republic of Egypt.

\section{The research sample}

The research sample was chosen randomly from the society sample and included (240) sports trainers of the trainers who work at (6) sports clubs in Cairo and Giza, ; these clubs are (Al Ahly club- Al Gazira club- Cairo club- $\mathrm{Al}$ 
Tersana club- Al Doqy fishing club- Al Zamalek club).

First: the main sample of the research:

This sample was chosen randomly from the research society and included (180) sports trainers; (30) trainers from each club of the following clubs (Al Ahly clubAl Gazira club- Cairo club- Al Tersana club- Al Doqy fishing club- Al Zamalek club).

Second: The exploratory sample of the research

Table (1)

The quantitative description of the research sample

\begin{tabular}{l|c|c|c|c}
\hline \hline Sr. & $\begin{array}{c}\text { The } \\
\text { governorate }\end{array}$ & The club & $\begin{array}{c}\text { The size of } \\
\text { main sample }\end{array}$ & $\begin{array}{c}\text { Size of } \\
\text { exploratory } \\
\text { sample }\end{array}$ \\
\hline \hline 1 & Cairo & $\begin{array}{c}\text { Al Gazira sports } \\
\text { club }\end{array}$ & 30 & 10 \\
\hline 2 & Cairo & Al Ahly club & 30 & 10 \\
\hline 3 & Cairo & $\begin{array}{c}\text { Cairo sports } \\
\text { club }\end{array}$ & 30 & 10 \\
\hline 4 & Giza & $\begin{array}{c}\text { Al Doqy fishing } \\
\text { sports club }\end{array}$ & 30 & 10 \\
\hline 5 & Giza & $\begin{array}{c}\text { Al Tersana } \\
\text { sports club }\end{array}$ & 30 & 10 \\
\hline 6 & Giza & $\begin{array}{c}\text { Al Zamalek } \\
\text { sports club }\end{array}$ & 30 & 10 \\
\hline \hline
\end{tabular}

Tools of data collecting:

The researcher has used the following tools for collecting the data:
It was chosen randomly from the society sample and out of the basic sample. This sample included (60) sports trainers; (10) trainers from each of the following clubs: (Al Ahly club- Al Gazira club- Cairo club- Al Tersana club- Al Doqy fishing club- Al Zamalek club). Table (1) shows the quantitative description of the two basic and exploratory samples of the research. 
sports activities at the Egyptian sports clubs (designed by the researcher).

Second: the scale of the organizational trust for the trainers of the sports activities at the Egyptian sports clubs (designed by the researcher).

The statistical manner used in the research:

- The descriptive statistics of the sample (the mathematical mean- the mediator- the standard deviation- the coefficient of torsion).

- Calculating the correlation coefficient by using Person Method.

- Estimating the stability by using Alpha Kronbakh coefficient.

Showing and discussing the results:

Table (2)

The mathematical mean, the standard deviation and the torsion coefficient for the sample responses to the dimensions of questionnaire of the human resources management strategies for the trainers of the sports activities in the Egyptian sports clubs $(\mathrm{N}=180)$

\begin{tabular}{l|l|c|c|c|c}
\hline \hline Sr. & \multicolumn{1}{|c|}{ The dimensions } & m & sun & L & $\begin{array}{l}\text { Difference } \\
\text { coefficient }\end{array}$ \\
\hline \hline 1 & $\begin{array}{l}\text { First: strategy of } \\
\text { attraction, choice and } \\
\text { appointment }\end{array}$ & 49.76 & 7.96 & $359 .-$ & 15.9 \\
\hline 2 & $\begin{array}{l}\text { Second: strategy of } \\
\text { training and } \\
\text { development }\end{array}$ & 45.55 & 2.97 & 020. & 6.5 \\
\hline 3 & $\begin{array}{l}\text { Third: strategy of } \\
\text { evaluating the } \\
\text { personnel's performance }\end{array}$ & 46.93 & 7.98 & $1.19-$ & 17.0 \\
\hline 4 & $\begin{array}{l}\text { Fourth: strategy of } \\
\text { incentives, rewards and } \\
\text { compensations }\end{array}$ & & & & 18.7 \\
\hline \hline
\end{tabular}

Table (2) shows the following:

- The torsion coefficient of the sample's responses to the dimensions of the two between $(+3,-3)$ and this indicates to the data moderation. questionnaires has confined 
- The values of the mathematical means of the sample's responses to the dimensions of questionnaire designed for the human resources management strategies for the trainers of the sports activities in the Egyptian sports clubs have confined between (49.76) for the first dimension and (40.01) for the second dimension.

- The dimensions of the questionnaire that is designed for the human resources

\section{Table (3)}

The mathematical mean, the standard deviation and the Convolution for the sample responses to the dimensions of the organizational trust scale for the trainers of the sports activities in the Egyptian sports clubs $(\mathrm{N}=\mathbf{1 8 0})$

\begin{tabular}{l|l|l|l|l|l}
\hline \hline Sr. & \multicolumn{1}{|c|}{ The dimensions } & m & sun & L & $\begin{array}{l}\text { Difference } \\
\text { coefficient }\end{array}$ \\
\hline \hline 1 & $\begin{array}{l}\text { First: the trust in the } \\
\text { colleagues in the sports } \\
\text { clubs. }\end{array}$ & 48.97 & 6.26 & -0.754 & 12.70 \\
\hline 2 & $\begin{array}{l}\text { Second: the trust in the } \\
\text { managers in the sports } \\
\text { clubs. }\end{array}$ & 53.64 & 4.10 & 0.378 & 7.60 \\
\hline 3 & $\begin{array}{l}\text { Third: the trust in the } \\
\text { higher management of } \\
\text { the sports clubs. }\end{array}$ & 38.91 & 5.53 & 0.296 & 14.20 \\
\hline $\begin{array}{l}\text { The total degree of the } \\
\text { organizational trust scale }\end{array}$ & 141.53 & 9.99 & 0.158 & --- \\
\hline \hline
\end{tabular}

Table (3) shows the following:

- The torsion coefficient of the confined between $(+3,-3)$ and sample's responses to the dimensions of the scale has

management strategies for the trainers of the sports activities in the Egyptian sports clubs have been ordered in descending order according to the value of the mathematical mean as follows (the strategy of attraction, choice and appointment- strategy of evaluating the personnel's performance- the strategy of training and development- the strategy of incentives, rewards and compensations).

\section{Assiut Journal For Sport Science Arts}


- The values of the sports clubs reached (141.53) mathematical means of the sample's responses to the organizational trust for the trainers of the sports activities in the Egyptian sports clubs have confined between 53.64) for the first dimension and (38.91) for the third dimension. - The value of the mathematical mean for the sample's responses to the scale of the organizational trust in a whole for the trainers of the sports trainers at the Egyptian

Table (4) and this indicates that the sample individuals have got high degrees of the organizational trust.

- The dimensions of the scale have been ordered in descending order according to the value of the mathematical mean as follows (the trust in managers of the sports clubsthe trust in the colleagues at the sports clubs- the trust in the higher management in the sports clubs).

The values of correlation for the sample responses between the dimensions of the questionnaire of human resources management strategy and the dimensions of the organizational trust scale for the trainers of the sports activities at the Egyptian sports clubs

$(\mathrm{N}=180)$

\begin{tabular}{l|c|c|c|c|c}
\hline \hline $\begin{array}{l}\text { Strategies } \\
\text { Organizational } \\
\text { trust }\end{array}$ & $\begin{array}{c}\text { The } \\
\text { statement }\end{array}$ & $\begin{array}{c}\text { Attraction, } \\
\text { choice and } \\
\text { appointment }\end{array}$ & $\begin{array}{c}\text { Training } \\
\text { and } \\
\text { development }\end{array}$ & $\begin{array}{c}\text { Evaluating } \\
\text { the } \\
\text { performance }\end{array}$ & $\begin{array}{c}\text { Incentives, } \\
\text { rewards and } \\
\text { compensations }\end{array}$ \\
\hline \hline $\begin{array}{l}\text { Trust in the } \\
\text { colleagues }\end{array}$ & $\mathrm{R}$ & -0.13 & 0.166 & -0.78 & 0.007 \\
\cline { 2 - 6 } & significance & 0.866 & 0.26 & 0.299 & 0.928 \\
\hline $\begin{array}{l}\text { Trust in } \\
\text { managers }\end{array}$ & $\mathrm{R}$ & 0.018 & -0.47 & 0.035 & -0.216 \\
\cline { 2 - 6 } & significance & 0.806 & 0.532 & 0.639 & -0.164 \\
\hline $\begin{array}{l}\text { Trust in higher } \\
\text { management }\end{array}$ & $\mathrm{R}$ & -0.089 & -0.028 & 0.208 & 0.27 \\
\cline { 2 - 6 } $\begin{array}{l}\text { Total degree of } \\
\text { the } \\
\text { organizational } \\
\text { trust }\end{array}$ & significance & 0.223 & 0.707 & 0.005 & -0.175 \\
\cline { 2 - 6 } & $\mathrm{R}$ & -0.50 & 0.69 & 0.52 & 0.19 \\
\hline \hline
\end{tabular}

*significance $(<0.05)$

Table (4) shows that:

- There is correlation with a

the strategy of training and statistical significance between the trust in the colleagues and development.

- There is correlation with a statistical significance between the trust in the higher 
management and the strategy of evaluating the personnel's performance.

- There is adverse correlation with a statistical significance between the strategy of incentives, rewards and compensations and both of (the trust in managers- the trust in the higher management).

- There is adverse correlation with a statistical significance between the strategy of incentives, rewards and compensations and the total degree of the organizational trust.

Second: discussing and interpreting the results:

Discussing and interpreting the results:

The first question:

"What are the strategies of human resources

management at the Egyptian sports clubs?"

- The results of the study in the field of knowing the strategies of the human resources management at the Egyptian sports clubs have come in accordance to the results shown in table (2), since they were in descending order according to the value of the mathematical mean as follows (the strategy of attraction, choice and appointment- the strategy of evaluating the personnel's performance- the strategy of training and development- the strategy of incentives, rewards and compensations), this means that the Egyptian sports clubs use the strategy of attraction, choice and appointment more than using the other strategies of the human resources management.

- The results of the current study agree with the results of the study conducted by "Sara Yahya" (2013), since they concluded that the strategy of attraction, choice and appointment came in the first place to be one of the most important strategies of the human resources management that used by the research sample.

- The results of the current study also come in accordance with the results of the stud conducted by "Thitle, M 2007), which concluded that the most important strategies of the human resources management were in descending order as follows (the strategy of attraction, choice and appointment- the strategy of incentives management- the strategy of performance 
management- the strategy of managing the multi- cultures).

- The results of this study also agree with the study conducted by (Walia, M 2012) which indicated that there is positive relation between the strategies of the human resources management and keeping the employees in these banks. Moreover, these strategies have contributed largely in choosing the proper employee for the proper job.

- The results of the current study agree with the results of the study was conducted by (Har, C., et al 2010) since the researchers concluded that the strategies of the human resources management contribute largely in choosing the proper personnel in the proper place with the required skills, they also contribute in choosing the proper incentive for encouraging the personnel with the required experiences and knowledge.

- The researcher sees that the strategy of attraction, choice and appointment warrants that the sports club will employ qualified and distinguished individuals to work at the club according to its needs. Through this strategy , the club will ensure that it will get a distinguished human element that saves the time and effort and achieves the required goals in the manner that achieves the competitive advantage, in particular, in the light of the lack of potentialities and the absence of control that is suffered by the sports clubs. On the other hand, the strategy of attraction, choice and appointment will maintain the efforts of the following human resources management that are practiced through the work in the club, namely (the strategy of evaluating the personnel's performance- the strategy of training and development- the strategy of incentives, rewards and compensations), since practicing these strategies by efficient persons from the beginning contributes in increasing the final product of human resource with a good quality.

- The researcher also sees that is based on the entire behaviors (the procedures- the decisions) that are executed $b$ the clubs, whether explicitly or implicitly, which are observed through the club society, including the sports trainers in their capacity as the working Assiut Journal For Sport Science Arts 
group of the study, which are represented in the following:

Specialized committees for planning for the club needs from the sports trainers continuously. The vacant jobs are also declared on the different media.

The managers of the sports activities at the club provide the club current and future needs from the sports managers to the higher management with a clear classification to the role and tasks of the sports trainers in different sports activities.

Informing all applicants for the sports trainer job with the results of the choice process and the declaration of the vacant jobs must indicate clearly to the advantages of working at the club.

Appointing at the different sports activities in the club in the light of the scientific qualifications and the appointment process must be based on declared rules that are based on the efficiency and experience as well as using the information network in the process of attracting the sports trainers to work at the club, in addition to providing many facilities to the distinguished sports trainers on appointing them.

Conducting tests and interviews for accepting the applicants to work as trainers in the sports clubs with providing material and moral incentives by the club for attracting the individuals with rare efficiency and skills to work as sports trainers in the club as well as conducting interviews for choosing the sports trainers.

Thus, the first question has been answered, namely:

"What ate the strategies of human resources management at the Egyptian sports clubs?"

The second question:

"What is the degree of the organizational trust for the trainers of the sports activities at the sports clubs?"

The results of the study in the field of recognizing the degree of the organizational trust for the trainers of the sports activities in the sports clubs as shown in table (3), since the value of the mathematical mean of the sample responses on the scale of the organizational trust in a whole for the trainers of the sports activities in the sports 
clubs was (141.53), this indicates that the individuals of the sample have got high degrees of the organizational trust. The dimensions of the scale were in descending order according to the value of the mathematical value as follows (the trust in the presidents of the sports clubs- the trust in the colleagues at the sports clubsthe trust in the higher management of the sports clubs), this means that the sample individuals enjoy high degrees of the organizational trust and the enjoy the trust in their managers.

The studies of the current study agree with the results of studies conducted by Hussien Al Azab, Dokhy Al Henaity and Abdullah Al A'kak (2009), since the researchers concluded that the sample's individuals enjoy high degrees of the organizational trust.

The researcher sees that the answer of the second question is in accordance with the result of the first question (the sample's individuals have high degrees of the organizational trust), since the sports trainer has acquired the organizational trust since his appointment procedures during dealing with his managers in the work. The previous results have shown that the sample's opinions revealed that the practices of this strategy are made with integration and transparency which in its turn increases the rates of the organizational trust for the sports trainers.

The researcher also sees that the order of the scale dimensions in descending order according to the value of the mathematical mean was as follows (the trust in the sports clubs- the trust in the workmates in the sports clubsthe trust in the higher management of the sports clubs) was due to the trainer's dealing with his direct manager, hence, the degree of the organizational trust is built through many situations. On the other hand, the sports trainer deals with the higher management in very limited way, almost in indirect way, since his dealing is made through his direct managers, thus, the amount of the trust he has in the higher management is made through his direct managers. The motives behind this trust come as result of a lot of the managers' characteristics according to the sample's individuals, since the 
sports trainers participated in the research find that their managers:

Have the technical skills and abilities that are necessary for the tasks of their position and they really deserve this position. They also sure that they get a lot of the training courses.

The managers are just in distributing the tasks and responsibilities on all personnel and they make the regular evaluation for all personnel continuously as well as the accuracy of the decisions they make.

They enjoy high accuracy in the results of the evaluation they made. They also enjoy with the integrity in nominating the individuals who deserve the promotion.

Thus, the second question is answered, namely:

"What is the degree of the organizational trust for the trainers of the sports activities in the Egyptian sports clubs?"

The third question:

"What is the relationship between the strategies of the human resources management and the organizational trust for the trainers of the sports

\section{activities in the Egyptian sports clubs?"}

The results of the study in the field of recognizing the relationship between the strategies of the human resources management and the organizational trust for the trainers of the sports activities at the Egyptian sports clubs as shown in table (4); since the results showed that there is a direct relation with a statistical significance between the dimension of the trust in the workmates and the strategy of training and development. The results also showed that there is direct relation with a statistical significance between the dimension of trust in the higher management and the strategy of evaluating the personnel performance. The results also showed that there is adverse relation with a statistical significance between the strategy of incentives, rewards and compensations the dimensions of (the trust in the managers- the trust in the higher management) and the total degree of the organizational trust.

The results of the current study come in accordance with the results of the study conducted by "Ahmed Al Baz 
Abdel Latif" (2015), since the results indicated that the trust in the workmates and the trust in the manager intervenes that relation between the work culture and the emotional obligation and there is positive relation with a statistical significance between them.

The results of the current study agree with the results of the study conducted by "Aya Hussine Al Sayed" (2014), since the results indicated that there are a positive moral effect between the evaluation transparency and the mutual organizational trust between the bosses and the subordinates.

The results of the current study differ from the results of the study conducted by (James $H$ 2010) which indicated that there is positive realtion between the degree of the organizational trust and the following variables (the performance level- the degree of effectiveness- the creativity).

- The researcher sees that the direct relation with a statistical significance between the dimension of trust in the workmates and the strategy of training and development comes from the training courses that the trainers receive in the club increase the level of their performance; this in its turn will be reflected on the dependence degree that each trainer grants to his colleague in order to perform the tasks of his job in different conditions. This trust was also acquired in the light of many characteristics which distinguish the strategy of training and development of the trainers' performance level, this was revealed by the sample's opinions which are distinguished by the following: - There is a comprehensive plan for defining the training needs for the sports trainers of all sports activities, in addition, there is a continuous evaluation for defining the effectiveness of the directed training courses as well as the authority that is responsible for supervising the training courses for all sports activities at the club (declaration- organizingevaluating.....).

The directed training courses are free for all sports trainers in different activities and all nominated trainers are obliged to attend these courses in addition to the directed training courses with the aim 
of preparing second queue of the distinguished sports trainers at the club.

The nomination for attending the directed training courses are made in the light of the work needs and there are directed training courses for the new sports trainers with the aim of preparing them to execute the required tasks.

The aim of the evaluation is to improve the performance not to catch the errors; and the results of the regular evaluation for the trainers are kept for the comparison in order to define the change that occurs in the level of the trainers' performance.

- The researcher also sees that the adverse correlation between the strategy of incentives, rewards and compensations and the two dimensions of (the trust in managers- the trust in the higher management) and the total degree of the organizational trust this because the trust of the sample individuals, as shown by the results, is strongly related to the procedures which improve the performance level (the strategy of training and development) and achieving the justice of the evaluation on which we apply the rule of reward and punishment (the strategy of evaluating the personnel's performance), this emphasizes that caring with the financial aspects is not absolute motive for developing the trust of the personnel.

Thus, the third question is answered, namely:

"What is the relationship between the strategies of human resources management and the organizational trust for the trainers of the sports activities at the Egyptian sports clubs?"

\section{Conclusions:}

1- The dimensions of the questionnaire for the human resources management strategies for the trainers at the Egyptian sports clubs are in descending order according to the value of the mathematical mean as follows (the strategy of attraction, choice and appointment- strategy of evaluating the personnel's performance- the strategy of training and development- the strategy of incentives, rewards and compensations).

- the value of the mathematical mean of the sample responses on the scale of the organizational trust in a 
whole for the trainers of the sports activities in the sports clubs was (141.53), this indicates that the individuals of the sample have got high degrees of the organizational trust.

The dimensions of the scale were in descending order according to the value of the mathematical value as follows (the trust in the presidents of the sports clubs- the trust in the colleagues at the sports clubsthe trust in the higher management of the sports clubs).

There is a direct relation with a statistical significance between the dimension of the trust in the workmates and the strategy of training and development.

The results also showed that there is direct relation with a statistical significance between the dimension of trust in the higher management and the strategy of evaluating the personnel performance.

There is adverse relation with a statistical significance between the strategy of incentives, rewards and compensations the dimensions of (the trust in the managersthe trust in the higher management) and the total degree of the organizational trust.

The recommendations:

In the light of the research results, the researcher recommends with the following:

1- Paying attention to develop the trust between the workmates through paying attention to the informal trainers' meetings that create the opportunity for interacting and exchanging the experiences with forming good relations.

2- Keeping on reinforcing the trust between the trainers and their managers through creating the culture characterized by the justice and transparency.

3- Taking the procedures that develop the closeness and the direct cooperation between the trainers and the higher management such as holding the meetings, forums and the directive interviews with the aim of developing the trust between the sports trainers and the higher management in their clubs.

4- Paying attention to the continuous modernization and development for the strategy of training and developing the personnel's performance which 
the results showed its direct effect through its direct relation to the dimension of trust in the workmates.

5- Paying attention to the continuous modernization and development for the strategy of evaluating the personnel's performance which the results showed its direct effect through its direct relation to the dimension of trust in the higher management.

\section{The references}

1- Ahmed Abied Al Rasheed \& Kayed Salama (2015) "the degree of the organizational trust in the private and governmental Kuwaiti Universities and its relation to the motivation of the teaching staff"- Journal of Al Qouds Opened University for the psychological and educational studies, the third volume, edition (12).

2-Ahmed Al Baz Abdel Latif (2015): "the relationship between the organizational trust and the organizational obligatory to the application to the personnel in the company of Middle Delta for Producing the electricity in Egypt"Master dissertation- faculty of commerce- Al Mansoura University.
3- Ahmed Bin Soliman Al Badrany (2010) "Realizing the organizational trust and its reltion to the organizational trust for the personnel at the security organizations- field study for the workers at the security inspection in the international Saudi airports"doctorate dissertation- Nyef Arabic University for the Security Sciences- Faculty of High studies.

\section{4- Ahmed Daw Al Beit Saleh} (2013) "The effect of the human resources management strategies in finding competitive advantages for the works organizations"doctorate dissertation- faculty of works management- Al Sudan University for the sciences and technology.

\section{5-Ahmed Hassan Al Wazab} (2012): "The organizational trust of the high schools managers in $\mathrm{Al}$ Taef and its relation to the creative behavior"- Master dissertationAum Al Qura UniversityK.S.A page (55).

6- Ahmed Mahdy Abdel Qader \& Ahmed Ibrahim Abu Sen (2012): "The effect of the practices of human resources management on the productivity at the industrial sector in Sudan by applying on 
Jyad Industrial Group"- The journal of sciences and cultureAl Sudan University for the sciences and technologyvolume (12)- edition (2) page (160).

\section{7-Ahmed Sayed Mustafa} (2010): "The human resources management, the contemporary principals and skills", third edition- the Academic LibraryCairo, page (17-18).

8- Asmaa Taha Nawry (2008): "the effect of the organizational trust and justice on the psychological combustion for the personnel at the ministry of high education and the scientific research"doctorate dissertation- faculty of administration and economy- Baghdad University, page (38).

9- Aya Hussine Al Sayed Abu Gabal (2014): "The effect of the administrative transparency on the mutual organizational trust between the leaders and subordinates, practical study on the commercial banks in Tanata"master dissertation- faculty of Commerce- Tanata University.

10- Caliskhan, Esra, N. (2010) "The Impact of Strategic Human Resource Management on
",Journal of Naval Science and Engineering, Vol.(6),No.(2) , PP.100:116.

11- Cook,F (2010):"Clinical Leadership That Works ", Journal of Nursing Management,March

Vol.(6),No.(2) ,PP. 55.

\section{2- Eman Ahmed}

Mohammed Azzab (2010): "the organizational trust and the competitive advantage of The secondary school in A.R.E in the light of some contemporary foreign experiences"doctorate dissertation- faculty of education- Ain Shams University, page (20).

\section{3- Eyad Fadel Al Tameemy} \& Shaker Gar Allah Al Khasahly (2008) "the role of the trust between the group individuals in determining the strategy of knowledge management- Filed study in the private Jordanian University"The Jordanian Journal for the applicable sciences- edition (2), volume (11).

14- Fahmy Khaliel Al Fahdawy (2005) "The relationship between the organizational trust and the organization leading level (practical analytical study)"- Al Nahda Journal- Cairo

Organizational Performance 
University- edition (4)- volume (6) page 56.

15- Hamed Kazem Metaeb \& A'amer Ali Al Atawy (2008): "The role of the organizational trust in improving the level of the situational and behavioral work outputs, practical study in the Nasseeg Al Dywanya Laboratory"- the journal of $\mathrm{Al}$ Qadesya University- faculty of business administration- edition (5)- volume (3)- page 25.

\section{6- Hamed Mustafa Hamed}

(2008): "The development of the human resources management in the sports clubs"- master dissertationfaculty of physical education for boys- Helwan University.

17- Har, C., Boon, T., Phaik, L.,\& Hsien, L., (2010): "The Impact of Human Resource Management Practices on $\mathrm{Km}$ :A conceptual Model. ",Australian Journal of Basic and Applied Sciences, Vol.4.

\section{8- Hussine Al Azab, Dokhy} Al Haneity \& Abdullah Al Akak (2009) "The effect of the social and job factors on the level of the administrative trust (practical study on the departments managers in the governmental bodies- Zafar governorate- Oman)"- Al Manara Journal- edition (17)volume (5).

19- James,H. (2010):" Astudy of Organizational Trust and Related Variable among Faculty members at HBUCS ", Unpublished of Dissertation , The University of Lowa, Iow, U.S.A.

\section{0- Mahfouz Gowda Ahmed} (2010): "The human resources management", Wael House for Publication- Oman- Jordan, page (40).

\section{1- Mohammed M. Ibrahim} (2009): "The human resources management"- The university house- Alexandria, page (55).

\section{2- Mohammed Sayed Gad}

Al Rab (2009): "The human resources management, strategic input for improving the competitive abilities" Wael House for prinitingJordan.

\section{3- Rana Nasser Al Taey} (2007) "The leading models and the organizational trust and 
its effect in achieving the organizational obligationpractical study for the opinions of sample of managers in the companies of the industrial sector"- master dissertationfaculty of administration and economy - Baghdad University, page (64).

24- Saad Ali Al Anzy \& Moayed Yousef Neama (2004) "the trust between its personal framework and its modern organizational concept"- The Iraqi Journal for the administrative sciencesfaculty of economy- Karbela University- edition (5)- page 54.

\section{5- Saied Shabban Hammed} (2008) "the role of human resources management strategies in improving the organizational performanceField study"- journal of accounting, administration and insurance- faculty of commerce- Cairo University, edition (41), page 77.

\section{6- Sakeyna Al Mohl}

\section{Mohammed \& Ahmed}

Ibrahim Abu Sen (2013)

"analyzing the reality of human resources management strategy and its effect on the performance in the Sudani communication companies: case study for the Sudani limited companies for communications"- journal of economic sciences- Al Sudan University for Sciences and Technology- edition (1)volume (14), page (138).

\section{7- Sara Yahya Ali (2013)} "Studying and analyzing the effectiveness of human resources management strategies in generating the competitive advantagecomparative study"- master dissertation- faculty of commerce- business administration departmentCairo University.

28- Thitle,M.,(2007):"Stratgic Positioning of Human Resource Management In Knowledge-based Organizations.”,Journal of Learning Organizations, Vol. (11),No.(1). 
29- Walia , kranti , (2012) . "Impact Of Human Resource Management (HRM) Practices on Employee Retention", International Journal of Research in IT \& Management , Vol.(8), No.(3), PP: 15-22.

\section{0- Zeinab Ismail Ibrahim} (2013) "the role of the organizational trust in supporting the strategic direction for the human resources management in the service governmental organizations- practical study on some Egyptian governmental universities"doctorate dissertation- faculty of commerce- Al Menofya University.

\section{1- Zyad Yousef Al Mashar \& Magdolin Assry (2012)}

"the effect of the evaluation system subjectivity on the organizational trust (practical study on male and female teachers in the directorates of education in Al Karak governorate- Jordan)"- The Jordanian journal in business administration, edition (4), volume (8), page (360). 